\title{
The protocol for the Families First Edmonton trial (FFE): a randomized community-based trial to compare four service integration approaches for families with low-income
}

\author{
Jane Drummond ${ }^{1 *}$, Laurie Schnirer², Sylvia So ${ }^{2}$, Maria Mayan², Deanna L Williamson $^{3}$, Jeffrey Bisanz ${ }^{4}$,
} Konrad Fassbender ${ }^{5}$ and Natasha Wiebe ${ }^{6}$

\begin{abstract}
Background: Families with low incomes experience an array of health and social challenges that compromise their resilience and lead to negative family outcomes. Along with financial constraints, there are barriers associated with mental and physical health, poorer education and language. In addition, vulnerable populations experience many services as markedly unhelpful. This combination of family and service barriers results in reduced opportunities for effective, primary-level services and an increased use of more expensive secondary-level services (e.g., emergency room visits, child apprehensions, police involvement). A systematic review of effective interventions demonstrated that promotion of physical and mental health using existing service was critically important.

Methods/Design: The Families First Edmonton Trial (FFE) tests four service integration approaches to increase use of available health and social services for families with low-income. It is a randomized, two-factor, single-blind, longitudinal effectiveness trial where low-income families (1168) were randomly assigned to receive either (1) Family Healthy Lifestyle plus Family Recreation service integration (Comprehensive), (2) Family Healthy Lifestyle service integration, (3) Family Recreation service integration, or (4) existing services. To be eligible families needed to be receiving one of five government income assistance programs. The trial was conducted in the City of Edmonton between January 2006 and August 2011. The families were followed for a total of three years of which interventional services were received for between 18 and 24 months. The primary outcome is the number of family linkages to health and social services as measured by a customized survey tool "Family Services Inventory". Secondary outcomes include type and satisfaction with services, cost of services, family member health, and family functioning. Where possible, the measures for secondary outcomes were selected because of their standardization, the presence of published norming data, and their utility as comparators to other studies of low-income families. As an effectiveness trial, community and government partners participated in all committees through a mutually agreed upon governance model and helped manage and problem solve with researchers.
\end{abstract}

Discussion: Modifications were made to the FFE trial based on the pragmatics of community-based trials.

Trial registration number: ClinicalTrials.gov NCT00705328

Keywords: Low-income families, Service integration, Healthy families, Recreation, Pragmatic trial

\footnotetext{
* Correspondence: jane.drummond@ualberta.ca

${ }^{1}$ Faculty of Nursing, University of Alberta, Edmonton Clinic Health Academy,

1140587 Avenue, Edmonton Alberta, AB T6G 1C9, Canada

Full list of author information is available at the end of the article
} 


\section{Background}

A pervasive challenge faced by Canadian health and social service providers is to promote health for vulnerable populations in a proactive and cost-effective manner. Indeed, families with low incomes continue to experience an array of health and social barriers that compromise their resilience, leading to negative family outcomes, and inhibiting access to available services. The relation between low income and poor health is well known. In a recent systemic review, researchers found higher rates of mental health problems among children with low socioeconomic status [1]. The Canadian infant mortality rate is two-thirds higher in low-income neighbourhoods than in the highest income neighbourhoods [2]. Low-income Canadian children are more likely than their higher-income peers to suffer from ill health and mental illness [3], to be hospitalized [4], to have lower levels of cognitive scores and educational attainment [5], to have compromised memory and self-regulation [6], and to experience major behavioural problems [6-15]. Living with a low income compromises parental health and ability to parent, threatens family resilience, and jeopardizes family-community relations $[16,17]$. The health of low-income parents influences their ability to attain and maintain employment [18-23]. In addition, the constraint in public expenditure and commensurate movement away from universal services [24], which began in the 1990s, continues to affect those living with low incomes the most.

\section{Low-income and the social determinants of health}

Based on decades of inquiry, the World Health Organization [25], the Public Health Agency of Canada [26], and the Canadian Medical Association [27] have agreed that health and well-being are largely shaped by social and economic contextual factors, which are collectively referred to as the "social determinants of health." Contextual factors such as low educational attainment and low-wage precarious employment negatively influence the health of low-income families and their members by limiting their capacity to (a) increase their income and (b) obtain and use health and social services.

\section{Increasing income}

Despite growth in the Canadian economy during the mid 2000s, which resulted in an increase in jobs and a decline in unemployment rates [28], the incidence of low income among Canadian families remains essentially unchanged $[29,30]$. Further, in Canada, having work does not preclude having a low income. For instance, in twoparent families with one earner, $23 \%$ have low incomes [31]. In female-headed single-parent families where the mother is employed, $43 \%$ are living on low incomes [32]. In Edmonton, the site of the study, 18.5\% of families and $26.5 \%$ of children have low income [33]. Provincially, decision-makers are interested in providing services to low-income families that are both beneficial and cost effective [34] (e.g. Alberta's Social policy framework [35] and the Results-based Budgeting initiative [36]).

Moving social assistance recipients from welfare to employment was a main goal of the 1990 s social policy reform across Canada. In these programs low-income recipients of social assistance are required to get jobs or engage in employability programs [37-40]. Evaluative studies of welfare-to-work initiatives in Canada and the U.S. [21,22,41-44] suggest that policy efforts to move parents from social assistance to employment have been successful $[22,42,44,45]$ but do little to ameliorate the negative health consequences of living on a low income. That is, welfare-to-work programs seem to influence parents' health and children's development only when increased parental employment is accompanied by increases to family income $[17,22,41,44]$. There are two ways to increase income in working families: increase income from employment and provide income supplements, such as the Self-Sufficiency Project [42,44]. The majority of parents who move from social assistance to employment plus income supplement continue to have family incomes below low-income cut-offs. Furthermore, their income tends to decline when supplements end $[42,44,46]$. Finally, the evidence is mixed on the effects of welfare-to-work programs on children $[17,22,41,44,47]$.

Evaluation studies of welfare-to-work continue [48] but controversy remains [49-51] because of the many unintended consequences of these programs. Insights from recent studies reveal that single low-income parents face significant day-to-day challenges when integrating work and family demands, such as arranging child care [52]. Further, the transition from welfare to work emphasises economic issues (lack of health benefits) that are a root cause of welfare dependency [53].

\section{Obtaining health and social services}

Since welfare-to-work initiatives, with or without income supplements, do not impact health in low-income families in a sustainable way, there is a need for interventions that are directly guided by the goal of enhancing health. The benefits of participating in health and social programs are well documented [46,54-58]. A consistent relation exists between family socioeconomic status and engagement/retention rate of families in health, social, educational, leisure, and cultural activities [7,8,59-61].

Barriers to the use of community-based health and recreation services cause low-income families to use primary health prevention and promotion services, including community resources and recreation, less often than other income groups [46,62-65]. For these families, personal barriers include (a) financial constraints, (b) under or unemployment, (c) mental and physical health problems, and 
(d) challenges to quality of life, such as communication difficulties associated with poor education and language barriers [66-70]. Families that overcome personal barriers often face barriers at the system level that include: fragmentation; narrowness of mandate; power differential created by provider expertise; and difficulty in access because of location, language, and hours of availability. Such service barriers lead to suboptimal outcomes and use of more expensive downstream societal resources.

In summary, low-income families face barriers to increasing their income and to obtaining a broad range of health and social services, thus negatively influencing their health and social outcomes. The evidence reviewed indicates that increasing access to service may be a direct and sustainable way to improve health and social outcomes in low-income families. An important goal for Canadian society must be to develop service-delivery policies and practices that reduce barriers to linkages between services and families in need, while being cost effective. This study focused on service integration approaches that actively link low-income families to healthy family lifestyle (e.g., health services, child care/schools, social supports) and to recreation.

\section{Families first Edmonton trial}

In the Families First Edmonton (FFE) trial, we randomized 1168 low-income families into four service integration approaches to test proactive linkages between low-income families and services existing in their communities.

\section{Family healthy lifestyle and family recreation as service integration approaches}

FFE was initiated after findings from When the Bough Breaks (WTBB), an award-winning Canadian study [24], were published. That study showed that that providing low-income families on social assistance with proactive comprehensive care (health promotion, employment retraining, and recreation activities for children) compared to allowing families be self-directed in finding these services, resulted in 15\% more exits from social assistance within 1 year and substantial savings to society in terms of social assistance pay-outs.

Primary health care is the first element of continuing health and is designed to connect families to community services concerned with the broad determinants of health, including health services, education, and social support $[71,72]$. It is accessible, continuous, comprehensive, and coordinated, and is provided as closely as possible to where people live or work. Primary health care delivered through in-house family support has been shown to enhance both parents' $[13,73,74]$ and children's well-being [73,75-78]. Social support accounts for a significant proportion of lowincome family adaptation $[79,80]$. It is likely that parental involvement with childcare and schools leads to a richer family social support network [81-83]. More importantly, it has also been found that children whose families are linked to their schools have better academic achievement [83].

Regarding recreation, children who are active and engage in positive recreational opportunities benefit in physical well-being, psychosocial health (e.g., less anti-social behaviour), and resilience [13,14,84-89]. The lack of skill development programs for low-income children imposes short- and long-term negative consequences [69]. Children's participation in recreation is also linked to positive impacts on family relationships [69,90] and parental adjustments that are related to positive child development outcomes $[74,84,91]$.

The FFE investigation tested the findings and probed the conditions and generalizability of WTBB for current social assistance environments. FFE differs from WTBB in many ways. First, an analytic framework that describes the outcomes and intervening variables founded the research questions and plan for data analysis. Second, the primary health care and recreational service integration approaches and supporting practices were described in detail and closely audited to enable transfer of the successful service integration approach. Third, the sample aimed to be more inclusive to allow for examination of a broad socio-economic profile of low-income families, thus allowing researchers to address the question of who benefits the most and under what circumstances, questions typically neglected in this type of research [92]. WTBB included only single-parent families (98.1\% female-headed) on social assistance. FFE included both single- and twoparent families. WTBB was conducted prior to the implementation of mandatory welfare-to-work initiatives. In Alberta, welfare-to-work initiatives require low-income families who receive income support to engage in employment or employment-related activities in exchange for income support once their youngest child is 12 months of age. Further, the sample from WTBB was predominately Euro-Canadian. FFE recruited participant families in an area where 54\% of Edmonton's Aboriginal population and $39 \%$ of Edmonton's visible minorities reside, thus allowing for analysis based on these characteristics. Families who do not speak English were given the opportunity to participate. Fourth, the role of family functioning was explored as an intervening variable between the service delivery models and the primary outcome (family linkage to services) and to secondary outcomes (costs and health). Fifth, the service delivery models in WTBB were implemented for one year. In FFE, the models will be implemented for up to two years with follow-up for three years. This design facilitated examination of short-, intermediate-, and longer-term outcomes. Sixth, the service delivery models of FFE were designed by service delivery professional and researchers to be simple, transparent, easily tracked, and sustainable. Thus FFE was designed to generate the types of knowledge that will be 
essential if FFE interventions are to be adapted and implemented elsewhere.

\section{Principles of service integration practice}

A systematic review of effective interventions for schoolaged children, 29 reviews of 1102 intervention studies [93], drove the selection of practice principles for service integration practices within the content areas of Family Healthy Lifestyle and Family Recreation. The studied interventions encompassed a variety of program orientations including promoting physical and mental health, enhancing educational outcomes, fostering positive emotional adjustments, and preventing problem behaviours, suicide, and child abuse. Analysis showed that successful programs have seven characteristics. First, they were holistic and integrated. The complexity of the life of the child, parent, and family is addressed. Intervention strategies that target diverse areas (e.g., mental and physical health, safety, education, recreation, and youth employment) are needed. Second, successful programs resulted from collaborations that are multi-level and multi-sectoral. Third, successful programs were capacity building. They provide opportunities to build skill, rather than focusing exclusively on eliminating undesirable problems and behaviours. Fourth, successful programs were client-centred. For example, culturally appropriate services are offered and transportation barriers are addressed. Fifth, successful programs were community-based in what is available and situated in families' neighbourhoods. Sixth, successful programs were long term, engaging at-risk children and youth long enough to show effects and enabling relationships between staff and participants to develop. Seventh, successful programs were well staffed with supportive personnel who are culturally similar to the population served. As a result, the practice principles selected to be embedded in the service integration content areas of Family Healthy Lifestyle and Family Recreation included family-centredness, cultural sensitivity, capacity building and reflection.

\section{Aim of the study}

This study focused on evaluating service integration approaches directed at increasing linkages between lowincome families and services existing in their communities. The primary research question was:

What are the effects of three community-based service-integration approaches (Family Healthy Lifestyle, Family Recreation and Comprehensive), as compared to a control model (Existing Services), on the number of linkages that families initiate and maintain with established health and social services?

The design of the study enabled a thorough examination of several additional questions that are critical for understanding the influence of different service-delivery models on family linkages with established services, costs, and health. Secondary research questions included:

1. What are the relative effects of different service integration approaches on specific characteristics of family linkages to established service (e.g., type of service, satisfaction with), and how do the frequency and type of involvement change over time?

2. What are the costs to service systems of each of the service-integration approach over time?

3. What are the physical and psychosocial health outcomes of family members, over time, associated with each of these service integration approaches?

In order to effectively contribute to policy change, it was important to identify concurrent and antecedent variables related to linkage, cost, and health outcomes, and to estimate the likely impact of these variables [94,95]. Tertiary research questions included:

4. What is the intervening role of family functioning (family problem solving, communication, parenting, connections to community) between each of the four service integration approaches and linkage to services, cost, and health outcomes for family members, and how does this role change over time?

5. To what extent does sociodemographic profile (e.g., ethnicity, immigrant status, education, occupation, family type, level of income, sources of income, security of housing, number of children) influence the relation between each of the four service integration approaches and linkage to service, cost, and health outcomes, and how does this influence change over time?

\section{Hypothesis}

We hypothesized that low-income families who receive community-based service-integration (i.e., Family Healthy Lifestyle, Family Recreation and/or Comprehensive) would initially increase linkages to services, and that costs to service systems would decrease as improvements to physical and psychosocial health of family members are realized over time.

\section{Methods/Design Study design}

FFE is a randomized, single-blind, longitudinal effectiveness trial with a 2 by 2 factorial design with three integration groups and a control group. The study was conducted in the City of Edmonton between January 2006 and August 2011. The study employed a multi-prong strategy to recruitment. Eligible families were invited to the study through five source programs for low-income families. In 
addition, posters and invitation packages were available at community agencies and through service workers. Information about the study was presented at community events where eligible families could inquire for more information. All families who received the source programs during the recruitment period were invited to participate in the study. Families were randomized after baseline data collection using a 1:1:1:1 allocation ratio. Those who were assigned to the intervention groups received between 18 and 24 months of service integration intervention. All families were followed by researchers for a total of three years with a minimum of ten interviews for data collection: two at baseline, and two at year 1 , year 2 , and year 3 , respectively.

\section{Eligibility criteria for participants}

The study focused on low-income families residing in City of Edmonton. To be eligible families needed to be receiving one of the five government assistance programs: (1) Income Support ("social assistance"), (2) Alberta Child Health Benefit, (3) City of Edmonton's Leisure Access program, (4) Alberta Adult Health Benefit, and (5) Capital Regional Housing. All these programs provide either financial assistance or access to affordable housing and recreation for low-income individuals or families in the city area. In addition, potentially eligible families would have at least one child younger than 12 years of age living in the household. Families were allowed to define themselves: thus, the definition of family is not confined to traditional dual-parent family or biological-parent family but includes others such as single-parent families, adoptive families, and grandparent led families.

\section{Exclusion criteria}

At recruitment, the study had three main exclusion criteria: (1) unwilling to commit to the full length of the study, (2) unwilling to provide researchers access to the focus child, or (3) non-English speaking families for whom researchers were unable to locate a relevant interpreter. After families were recruited, they were free to withdraw from the study at any time without penalty, with the understanding being that the intervention to which they were assigned was terminated. Although the study focused on low-income status, families with sufficient improvement in household income were not excluded from the study, due to recognition of income fluctuation in some vulnerable populations. After recruitment, families were no longer eligible to participate if they moved outside of the study area, the City of Edmonton.

\section{Details of the intervention}

FFE community partners funded the practice content areas. The amount of direct service was constrained by two things: 1) the desire to evaluate the effect of a small intervention on the use of existing service and 2) the realities of the funders' budget. For these reasons, Family Recreation was funded for 1.4 hours per month per participant family, Family Healthy Lifestyle was funded for 3.5 hours per month, and Comprehensive was funded for 4.6 hours per month.

The practice content areas (recreation and family healthy lifestyle), practice principles (family-centredness, cultural sensitivity, capacity building, and reflection) and hours of direct service were essential elements of logic model development followed by request for proposals (RFP). The logic model elements formed the basis of an FFE RFP from interested community agencies.

Existing service providers in Edmonton were invited to submit a proposal for delivery of the FFE interventions. Evaluation of the proposals for service delivery led to the selection of a service delivery partnership of four community agencies called Families Matter. The Families Matter partners included: YMCA of Edmonton, Multicultural Health Brokers Co-operative, KARA Family Resource Centre, and Bent Arrow Traditional Healing Society. To achieve practice rigor Families Matter relied on: hiring practices that target selected front-line provider education and experience; in-service training directed at developing knowledge and behaviours believed to match the practice principles and content area selected; and supervision approaches.

Community-based intervention, when delivered in a research project, risks losing intervention fidelity for at least two reasons: (a) use of general practice principles and very broadly identified content area within which to practice, and (b) intervention drift [96]. In addition, there is a culturally based reluctance by service providers to submit to rigorous oversight of community developed practices.

For these reasons, action research methods were used to record and monitor the delivery of the service integration approaches. An administrative database was jointly developed to include qualitative and quantitative methods of recording practice to be used to calculate dose and to audit practices. In addition, the administrative and supervisory staff of Families Matter met weekly with the researchers to review and internalize the elements of the FFE service delivery logic model, which built the relationship and internalized the need for intervention fidelity. Similarly, a researcher spent half a day each week with the supervisors and family workers, focussing on trouble-shooting the practices associated with recording the practices in the data base and on the need for fidelity to the three service integration groups. Families Matter also assigned family workers and supervisors to only one service integration approach in order to support intervention fidelity. Lastly, focus groups and individual interviews were held, with supervisors and family 
workers, over the course of the 18 months of service delivery in order to specify the practices used in service integration. At the end of the project, a Service Integration Tool Kit was published [97].

\section{Outcome measures}

The study aimed to determine which of the interventions impact accessibility in the most efficient and effective manner. Where possible, the measures were selected because of their standardization, the presence of published norming data, and their utility as comparators to other studies of low-income families.

The primary outcome, family linkage to health and social services, was measured using an innovative tool, "Family Services Inventory" (FSI). This tool was developed by a health economist, in consultation with FFE researchers. The FSI adopts a societal perspective and measures public and private consequences for families. The FSI was developed to maximize precision while minimizing patient burden and recall bias. A FSI toolkit comprised in-service training materials for data collectors, a user manual, a codebook, and a calendar (a memory aid to reduce recall bias). Annual data capture of resource use during the prior month was conducted in face-to-face interviews. Due to variations in scheduling interviews, resource use is normalized to the observation period (time between first and second visit). Characteristics of services and data allowing for costing of services were also collected in the FSI.

An overview of measures associated with the primary, secondary and intervening outcomes is found in Table 1.

\section{Data collection and management}

Data were collected at baseline, prior to randomization, and then every 12 months for three years. One adult respondent per family was selected based on familiarity with the children. A focus child was randomly selected (using computer-generated randomized lists stratified by number of eligible children) amongst the children within the household at screening. When appropriate, children's data were collected from the focus child. During data collection phase, follow-up data collections were conducted annually for all families. Research assistants who had established rapport with families since first contact arranged each data collection. Data collectors, blind to the group assignment, collected data during home visits.

Table 1 Outcomes, measures, and instruments

\begin{tabular}{|c|c|c|}
\hline Outcome & Measure & Instrument \\
\hline & $€$ Primary Outcomes $€$ & \\
\hline $\begin{array}{l}\text { Linkages between low-income } \\
\text { families and established services } \\
\text { in their communities }\end{array}$ & Average number of times the family linked to services & Family Services Inventory (FSI) \\
\hline \multirow[t]{2}{*}{ Quality of life } & Preference based measures & $\begin{array}{l}\text { Visual Analogue Scale (EQ VAS) Australian Quality of } \\
\text { Life (AQoL) }\end{array}$ \\
\hline & $€$ Secondary Outcomes $€$ & \\
\hline $\begin{array}{l}\text { Characteristics of linkages } \\
\text { between families and services }\end{array}$ & Type of service, satisfaction & FSI \\
\hline Costs to service systems & Costs of services linked to & FSI \\
\hline Adult physical health & General health status & $\begin{array}{l}\text { Single general health item from National } \\
\text { Longitudinal Survey of Children and Youth (NLSCY), } \\
\text { EQ-5D }\end{array}$ \\
\hline Adult psychosocial health & $\begin{array}{l}\text { Somatization, obsessive-compulsive, interpersonal sensitivity, } \\
\text { depression, anxiety, hostility, phobic anxiety, paranoid } \\
\text { ideation, psychoticism, self-esteem }\end{array}$ & $\begin{array}{l}\text { Symptom Checklist (SCL-90-R), Self-Esteem } \\
\text { Inventory }\end{array}$ \\
\hline Linkages to community & $\begin{array}{l}\text { (a) Perceived social functions and provisions obtained from } \\
\text { relationships with others; (b) social and civic participation; } \\
\text { (c) barriers to participation; (d) neighbourliness }\end{array}$ & $\begin{array}{l}\text { (a) Social Provision Scale; (b) items from the Health } \\
\text { and Participation survey; (c) Left Out survey; (d) } \\
\text { items from NLSCY }\end{array}$ \\
\hline Child physical health & $\begin{array}{l}\text { General health status, chronic conditions, injuries, nutrition, } \\
\text { sleep pattern, risk behavior }\end{array}$ & 40 items from NLSCY \\
\hline Child psychosocial health & $\begin{array}{l}\text { Socio-emotional development, personality, behavioral } \\
\text { problems, attitudes, mental health }\end{array}$ & Behavioral Assessment System for Children (BASC) \\
\hline Child Achievement & Spelling, Arithmetic, Reading, Receptive Vocabulary & $\begin{array}{l}\text { Wide Range Achievement Test; Peabody Pictorial } \\
\text { Vocabulary III }\end{array}$ \\
\hline Family Functioning & (a) Problem solving \& communication skills, (b) parenting, & McMaster Family Assessment device \\
\hline Socio-demographics & $\begin{array}{l}\text { Ethnicity, immigration status, education, occupation, family } \\
\text { type, level of income, source of income, security of housing, } \\
\text { number of children, neighbourhood }\end{array}$ & Items from NLSCY \\
\hline
\end{tabular}


FFE researchers adopted a professional human resource model with a data collection supervisor who oversaw 29 data collectors and 36 interpreters. We adopted this model because (a) a number of our instruments are standardized measures requiring psychometric assessment skills, and (b) it enhanced our ability to attract and retain a staff with adequate credentials and experience. Most of our data collectors had completed or were working toward their Master's degrees in a variety of health and social science fields. Data collectors were required to work evening and weekends, to be responsive to the schedules of the families, and all were rigorously trained on the data collection process, crisis management, and cultural sensitivity. A detailed manual of operations was available to the research assistants and data collectors at the coordinating office. Due to the volume of the data collected and to avoid fatigue of the primary participants, each data collection point consisted of two visits approximately 28 days apart. The 28 days lapse also allowed for a prospective collection of the services accessed by the family.

All data were collected using standardized case report forms by trained data collectors and then faxed to the Epidemiology Coordinating and Research (EPICORE) Centre - a clinical trials and health services research centre within University of Alberta, for data entry. EPICORE was responsible for data storage and quality assurance with the help of the data collection team. The database was coded in Microsoft Visual FoxPro V7.0. The use of free text fields and open-ended questions were eliminated from the forms, wherever possible. Simple (e.g., aberrant values, missing values) and complex verification rules were applied. Study subjects were identified by a unique study number assigned at time of enrolment. The study participants' personal information was not included in the database. Confidential contact information and documents containing the link between the primary parent's and focus child's names and the assigned study number were stored in locked file cabinets at the FFE coordinating office. Sixty randomly sampled from the first 200 baseline data files (all forms in part 1 and 2) were audited. The transcription error rate was less than $1 \%$ (5 errors were identified).

\section{Randomization}

The random allocation sequence was computer generated using $\mathrm{R}$ version 2.8.1 software.

We used permuted blocks of 8 and 12, stratified by type of income (Income Support receipts versus other source programs) and age of the focus child (0 to 3.9, 4 to $6.9,7$ to $9.9,10$ to 12.9 years).

\section{Allocation to experimental group and implementation} The intervention assignments were concealed on serially numbered, opaque, sealed envelopes. After the baseline data collection was completed, research assistants phoned the families and then opened randomization envelopes that were pre-stratified according to low-income status (i.e., receiving income supports vs. other source programs) and age of the Focus Child. Families were informed of their group assignment at that time. Research assistants explained the next steps to families. For those allotted to the intervention groups, their contact information was passed onto the service delivery workers. Research assistants explained to families that researchers would be in contact again for follow-ups, but families could contact them before then if they were moving or had any concerns about the study.

\section{Blinding}

The data collectors and the investigators were blinded from the group assignments. The families, the service delivery workers and the research assistants were not blind to the group assignments at any point in the trial. Investigators were unblinded when the datasets were cleaned (January 2012).

\section{Sample size}

Projecting a moderate $(\mathrm{f}=0.25)$ and even a small $(\mathrm{f}=$ 0.10 ) intervention effect size (mean divided by standard deviation), given an alpha of 0.05 and a $25 \%$ attrition rate, the study proposed an initial sample size of 300 families per group to detect any significant difference between the four groups (power was 0.99 and 0.72, respectively). The study randomized approximately 290 families to each group. The overall alpha value was not controlled for multiple comparisons. No interim analyses were planned.

\section{Statistical methods}

Most analyses will follow the intent-to-treat principle. The last-observation-carried-forward method will be used to impute missing data to maintain the integrity of the data set. Data will be analyzed using Stata MP 13.0 and SPSS 21.

\section{Primary analysis}

The data will be analyzed using linear regression including terms for the healthy family lifestyle and family recreation service-integration approaches, their interaction and, where appropriate, time (a repeated measure). If the distribution of the primary outcome is right-skewed and cannot be transformed to a normal distribution, Poisson regression will be used. Estimates and corresponding 95\% confidence intervals will be reported. The income group (Income Support vs. other source program) and the age of the focus child corresponding to strata variables in randomization will be included in the model. 


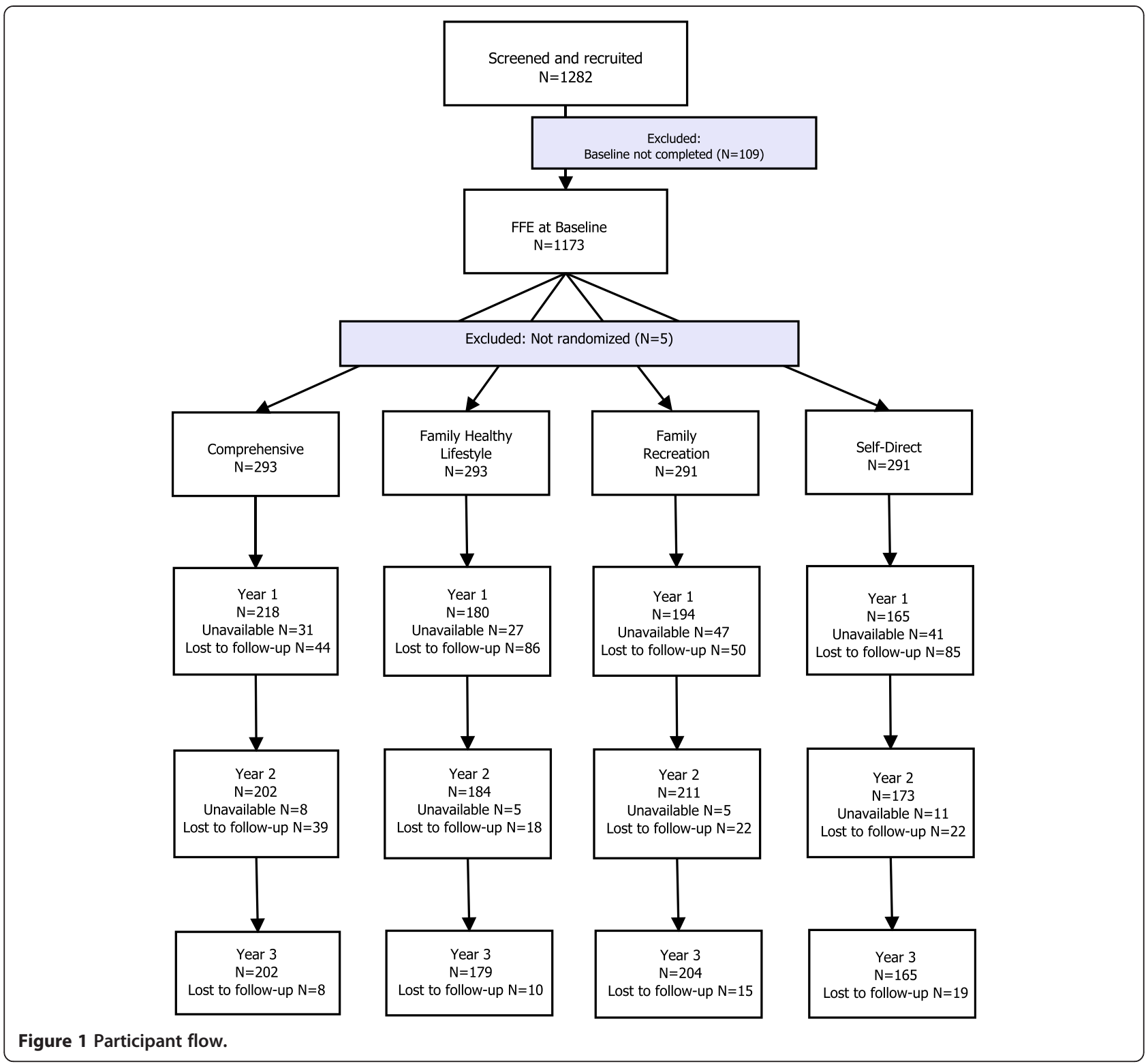

Analysis of the FSI and quality of life data will be guided by the Canadian guidelines for the economic evaluation of health technologies [98], which comprises a five-part analysis. Part 1 will focus on identifying and describing the differences in use of social and health system services. Part 2 will result in the translation of these differences into dollar values, including the valuation of the intervention. Part 3 will focus on identifying and measuring the differences in quality of life for the children, parents and families. Part 4 will integrate the costing and quality of life information into a formal cost-utility analysis. Beginning with a budget impact analysis, Part 5 will examine the implications of the findings from an administrative and policy perspective.

\section{Other analyses}

Additional variables to be considered in exploratory analyses include ethnicity, immigrant status, education, occupation, family type (e.g., single-parent families), level of income, sources of income (e.g., part-time), security of housing, number of children, region of the city. Residual, leverage, and influence diagnostics will be examined. For secondary outcomes, the four groups will be analyzed using appropriate modelling, such as linear regression, when the data are normal and logistic regression when the data are dichotomous. To study relations between family functioning and interventions over time, latent growth curve analysis will be used [99]. This method provides a comprehensive framework for studying latent variables over time by combining the strengths of structural 
Table 2 Losses and exclusions

\begin{tabular}{|c|c|c|c|}
\hline $\begin{array}{l}\text { Reasons for } \\
\text { withdrawal }\end{array}$ & $\begin{array}{c}\text { Before } \\
\text { randomized }\end{array}$ & $\begin{array}{c}\text { After } \\
\text { randomized }\end{array}$ & $\begin{array}{c}\text { Reasons for } \\
\text { withdraw (count) }\end{array}$ \\
\hline Not interest in & 55 & 18 & 73 \\
\hline Too busy/No time & 47 & 40 & 87 \\
\hline $\begin{array}{l}\text { Move out of study } \\
\text { area }\end{array}$ & 10 & 88 & 98 \\
\hline Family circumstances & 8 & 9 & 17 \\
\hline $\begin{array}{l}\text { Problems with } \\
\text { research }\end{array}$ & 6 & 4 & 10 \\
\hline $\begin{array}{l}\text { Problems with } \\
\text { randomized design }\end{array}$ & 5 & - & 23 \\
\hline $\begin{array}{l}\text { Problems with services } \\
\text { allotted }\end{array}$ & - & 18 & 18 \\
\hline Health & 3 & 5 & 8 \\
\hline Kids not interests in & 3 & 1 & 4 \\
\hline $\begin{array}{l}\text { Too much time past } \\
\text { since last contact }\end{array}$ & 3 & 0 & 3 \\
\hline Cultural differences & 1 & 0 & 1 \\
\hline Stigmatization & 0 & 1 & 1 \\
\hline Unknown & 18 & 5 & 23 \\
\hline Grand Total & 159 & 189 & 366 \\
\hline
\end{tabular}

equation modelling. This approach will enable modelling of the interaction among key variables, with the statistical techniques associated with longitudinal data analysis, which will allow us to study how these variables and their relations change over time. To exploit the power of latent growth curve analysis we will first develop and test theoretically derived and empirically based models designed to link variables using structural equation modelling methods at one point in time. Once we have developed and tested our initial models, we will extend our analyses by adding a growth parameter to each model so we can evaluate change over many periods in time. This combination of modelling variables within and between time periods has the potential to increase our understanding of variation while expanding the scope and value of the study.

\section{Ethical considerations}

This study protocol was approved by a special interdisciplinary ethics committee, led by the Faculty of Education, University of Alberta, Edmonton, Canada and Director (file number Pro00000144) of the then newly formed Human Research Protections Office. Ethical review for subsequent changes in the protocol, which are described below, were reviewed and approved. Although this is a community-based randomized controlled trial (RCT), partners do not have access to the original data and researchers do not receive any salary or other compensation during the trial.

Interested families contacted the community-based research office to learn about the study and ask questions.
Families in which English was a second language were offered the option of an interpreter during all interactions (e.g., on the phone setting up appointments, during the times the study was explained, during data collection). At the first home visit, each family was given written information about the study, which the data collector reviewed verbally. Written informed consent was obtained prior to study entry and data collection. Families were given an honorarium at each data collection period ( $\$ 25$ in early data collection periods and $\$ 30$ at the final data collection period).

\section{Discussion}

Modifications were made based on the pragmatics of community-based trials.

\section{Recruitment}

The investigators intended to recruit families in six months with three main eligibility criteria. It was planned that families must (a) have received one of the two source provincial programs, either Income Support or Alberta Child Health Benefits, continuously for the past six months, (b) reside in the central and North-east quadrants of the City of Edmonton, and (c) have at least one child younger than 12 years of age. The number of families in the sampling frame that met the original criteria was estimated to be about 5000. In fact, within six months of recruitment it was apparent that the target would not be reached. The actual response rate using these eligibility criteria was about $10 \%$.

The research team reviewed the recruitment process and eligibility criteria, and concluded: (1) all currently eligible families had already been invited; (2) the original eligibility criteria excluded many low-income families who were not currently on the two pre-identified source programs. Many immigrants or those on federally funded aboriginal treaty programs were not entitled to or were unaware of the two provincial programs. In addition, some eligible families were opting not to apply for these programs.

To increase the recruitment number and to ensure a representative sample of low-income families, the eligibility criteria were relaxed and extended: (1) the requirement that families had to have been receiving the source program for at least 6 months was waived; (2) source programs were added and (3) recruitment was expanded from central and northeast to the whole City of Edmonton (pop. $\approx 800,000$ ).

\section{Duration of intervention and follow-up data collection schedule}

As a result of expanding the recruitment period to 24 months, those enrolled during the last 6 months of recruitment only received up to 18 months of services rather 
than 24 months. Originally FFE was planned to be a fiveyear research project with eight visits for eight data collection points (baseline, 6 mos., 12 mos., 18 mos., 24 mos., 36 mos., 48 mos., 60 mos.). To increase the accuracy of the service utilization data, the research team adopted a prospective approach resulting in having two visits for each data point (16 home visits). To contain costs, the FFE Steering Committee in consultation with the research team approved dropping four data points: 6 mos., 18 mos., 48 mos., and 60 mos. That is, the FFE trial collected data from each family once a year for three years but data collection activity was spread over five years (accounting for the expanded recruitment period).

\section{Participant flow}

Figure 1 describes, the number of participants successfully screened and recruited and, for each group, the number of participants who were randomly assigned and received intended treatment.

Of the families who were contacted and expressed interests in the study, 1282 families were successfully screened and met recruitment criteria. Because some families withdrew and contact with others was lost, only 1168 families were randomized into the four groups.

\section{Losses and exclusions after randomization}

As indicated in Figure 1, during the process participants could either withdraw (i.e., lost to follow-up) or be 'dormant' for some of the data collection points (i.e. unavailable). At 36 months we were able to collect data from 748 families; data from 414 families were lost (135 Existing Services, 88 Family Recreation, 110 Family Healthy Lifestyle, and 91 Comprehensive). Table 2 shows reported reasons for withdrawal.

\footnotetext{
Abbreviations

CUP: Community-university partnership for the study of children, youth, and families; EPICORE: Epidemiology coordinating and research centre; EQ VAS: EQ visual analogue scale; FFE: Families first edmonton trial; FSI: Family services inventory; GSRM: Governments of Canada strategic reference models; NLSCY: National longitudinal study of children and youth; RCT: Randomized controlled trial; RFP: Request for proposal; WTBB: When the bough breaks.
}

\section{Competing interests}

KF and NW are consultants to the team. Notwithstanding, the authors declare that they have no competing interests and are not and have not been employed by the funding bodies that include: Alberta Heritage Foundation for Medical Research (AHFMR), and Canadian Institute for Health Research (CIHR), Canadian Health Services Research Foundation (CHSRF).

\section{Authors' contributions}

The authors all played significant roles in the study. JD (Principal Investigator), LS (Research Director, RCT), SS (Research Coordinator, RCT), MM (Research Director, Collaboration), DW (Lead, Family Data Analysis), JB (Lead, Child Data Analysis), KF (Lead, Service and Economic Analysis), and NW (Bio-statistician) have all been part of the development, implementation and analyses. JD, LS, and SS drafted this manuscript; all authors provided comments on the drafts and have read and approved the final version.

\section{Authors information}

Randomized controlled trials are rare in community-based intervention research and demand an interdisciplinary team that includes researchers with strong content knowledge, methodological skills, and collaborative nature. FFE managed by the Community-University Partnership for the Study of Children, Youth, and Families (CUP), an umbrella organization co-owned by academic, government, and community leaders. In July, 2000, CUP was formed to promote reciprocal, sustained, and mutually beneficial interactions among researchers, practitioners, and policymakers in research, education, and knowledge mobilization. JD, LS, MM, JB, DW all played leadership roles in CUP on and off campus. For more information, please visit www.cup.ualberta.ca or http://www.familiesfirstedmonton.ualberta.ca/.

\section{Acknowledgement}

The FFE trial was conceived, planned, implemented and disseminated by the FFE Partnership consisting of 12 community/government organizations and a core set of researchers from a 15 member interdisciplinary research team. It is designed to provide clear evidence for health and social policymakers about the influence of alternate service-delivery models and practices on enhancing and sustaining low-income family linkages to available services. The funding for the study was received through peer-reviewed funding agencies (Canadian Institutes of Health Research, Canadian Health Services Research Foundation, Alberta Heritage Foundation for Medical Research), government support (Alberta Employment and Immigration, City of Edmonton) and community foundations (Edmonton Community Foundation, Stollery Charitable Foundation, United Way of Edmonton Capital Region) and private funders (an anonymous donor who had no role in the study design and will play no role in the interpretation of data or writing of manuscripts arising from the data).

The authors would like to acknowledge and thank all research staff, Families Matter partners and service intervention staff, interpreters from the Multicultural Health Brokers, EPICORE, and our community and government partners. Last, we want to thank the families for participating. Their time and effort were greatly appreciated.

\section{Author details}

${ }^{1}$ Faculty of Nursing, University of Alberta, Edmonton Clinic Health Academy, 1140587 Avenue, Edmonton Alberta, AB T6G 1C9, Canada. ${ }^{2}$ Faculty of Extension, University of Alberta, Edmonton, AB T5J 4P6, Canada. ${ }^{3}$ Department of Human Ecology, Faculty of Agricultural, Life \& Environmental Sciences, University of Alberta, Edmonton, AB T6G 2R3, Canada. ${ }^{4}$ Department of Psychology, Faculty of Arts, University of Alberta, Edmonton, AB T6G 2E9, Canada. ${ }^{5}$ Department of Oncology, Faculty of Medicine \& Dentistry, University of Alberta, Edmonton, AB T6G 1C9, Canada. ${ }^{6}$ Department of Medicine, Division of Nephrology, University of Alberta, Edmonton, AB T6G 1C9, Canada.

Received: 12 November 2013 Accepted: 6 May 2014

Published: 19 May 2014

\section{References}

1. Reiss F: Socioeconomic inequalities and mental health problems in children and adolescents: a systematic review. Soc Sci Med 2013, 90:24-31.

2. Canadian Institute of Child Health $(\mathrm{ClCH})$ : The health of Canada's children: $A$ CICH profile. 3rd edition. Ottawa: Canadian Institute of Child Health; 2000.

3. Spady DW, Schopflocher DP, Svenson LW, Thompson AH: Prevalence of mental disorders in children living in Alberta, Canada, as determined from physician billing data. Arch Pediatr Adolesc Med 2001, 155(10):1153-1159.

4. Guttmann A: Child poverty, health and health care use in Canada. Paediatr Child Health 2001, 6(8):509-513.

5. Dooley M, Stewart J: Family income and child outcomes in Canada. Can J Econ 2004, 37(4):898-917.

6. Yoshikawa H, Aber $J$, Beardslee WR: The effects of poverty on the mental, emotional, and behavioral health of children and youth. Am Psychol 2012, 67(4):272-284

7. Lipman EL, Offord DR, Boyle MH: What if we could eliminate child poverty? the theoretical effect on child psychosocial morbidity. Soc Psychiatry Psychiatr Epidemiol 1996, 31(5):303-307.

8. Ross DO, Roberts PW: Income and child well-being: a new perspective on the poverty debate. Ottawa: Canadian Council on Social Development; 1999.

9. Willms JD: Vulnerable children: findings from Canada's national longitudinal survey of children \& youth. Edmonton, Canada: University of Alberta; 2002. 
10. David P. Ross, Mark Kelly, Katherine Scott: Child poverty: what are the consequences? Kanata: Canadian Council on Social Development; 1996.

11. Brooks-Gunn Jeanne, Greg J.Duncan, Pia Rebello Britto: Are socioeconomic gradients for children similar to those for adults? achievement and health of children in the united states. In Developmental health and the wealth of nations: social, biological, and educational dynamics. Edited by Daniel P. Keating, Clyde Hertzman. New York: Guilford Press; 1999:94-124.

12. Duncan GJ, Brooks-Gunn J, Klebanov PK: Economic deprivation and early childhood development. Child Dev 1994, 65(2, Children and Poverty):296-318.

13. Wade TJ, Pevalin DJ, Brannigan A: The clustering of severe behavioural, health and educational deficits in Canadian children: preliminary evidence from the national longitudinal survey of children and youth. Can J Public Health 1999, 90(4):253-259.

14. Evans GW: The environment of childhood poverty. Am Psychol 2004 59(2):77-92.

15. Alberta Health and Wellness, Office of the Chief Medical Officer: Let's talk about the early years: early childhood development. [www.health.alberta. ca/documents/CMOH-Lets-Talk-Early-Years-2011.pdf]

16. Luthar SS: Poverty and Children's adjustment. Developmental clinical psychology and psychiatry. Thousand Oaks, CA: SAGE Publications; 1999

17. Zaslow M, Moore KA, Tout K, Scarpa J, Vandivere S: How are children faring under health reform? In Welfare reform: The next Act. Volume 32. Edited by Weil A, Finegold K. Washington, DC: The Urban Institute; 2002:79-101.

18. Browne G, Byrne C, Roberts J, Schuster M, Ewart B, Gafni A, Watt S, Ashford $Y$, Jamieson $E$ : Resilience and vulnerability in mothers and children receiving social assistance: prevalence, correlates, and expenditures. Clin Excellence Nurse Pract 1997, 1(5):312-323.

19. Jayakody R, Stauffer D: Mental health problems among single mothers: implications for work and welfare reform. J Soc Iss 2000 56(4):617-634.

20. Lennon $\mathrm{MC}$, Blome J, English K: Depression among women on welfare: a review of the literature. J Am Med Womens Assoc 2002, 57(1):27-31. 40.

21. Michalopoulos C, Schwartz C, Adams-Ciardullo D: What works best for whom: Impacts of 20 welfare-to-work programs by subgroup. New York: Manpower Demonstration Research Corporation; 2000.

22. Morris PA, Huston AC, Duncan GJ, Crosby DA, Bos JM: How welfare and work policies affect children: A synthesis of research. New York; NY: Manpower Demonstration Research Corporation; 2001.

23. Sweeney EP: Recent studies indicate that many parents who are current or former welfare recipients have disabilities or other medical conditions. Washington, DC: Center on Budget and Policy Priorities; 2000

24. Browne G, Byrne C, Roberts J, Gafni A, Whittaker S: When the bough breaks: provider-initiated comprehensive care is more effective and less expensive for sole-support parents on social assistance. Soc Sci Med 2001, 53(12):1697-1710.

25. World Health Organization: The determinants of health. [http://www.who. int/hia/evidence/doh/en/]

26. Public Health Agency of Canada: What determines health? [http://www. phac-aspc.gc.ca/ph-sp/determinants/index-eng.php]

27. Canadian Medical Association: Health care in Canada: what makes Us sick? [http://www.cma.ca/advocacy/what-makes-us-sick]

28. Statistics Canada: Perspectives on labour and income: trends in employment and wages, 2002 to 2007. [http://www.statcan.gc.ca/pub/75001-x/2008109/article/10694-eng.htm]

29. Statistics Canada: Income of Canadian families, 2001 census. [http://www5. statcan.gc.ca/bsolc/olc-cel/olc-cel?catno=96F0030XIE2001014\&lang=eng]

30. National Council of Welfare: Poverty profile 1999. [http://publications.gc.ca/ collections/collection_2011/cnb-ncw/H67-1-4-1999-eng.pdf]

31. Sauvé R: The current state of Canadian family finances - 2011-12. Ottawa: Vanier Institute of the Family; 2012.

32. The Vanier Institute of the Family: Profiling Canada's families II. Ottawa, Canada: Vanier Institute of the Family; 2000.

33. Capital Health: Annual report of the medical officer of health: How healthy are we? 2003. Edmonton: Capital Health; 2003.

34. Government of Alberta: Guide to services for lower-income Albertans. Edmonton, Canada: Government of Alberta; 2004.

35. Government A: Alberta's social policy framework. Edmonton, Canada: Alberta Government; 2013

36. Alberta Treasury Board and Finance: Results-based budgeting. [http://www. finance.alberta.ca/business/budget/results-based-budgeting/index.html]
37. Beauvais C, Jenson J: Two policy paradigms: family responsibility and investing in children. Ottawa: Canadian Policy Research Networks; 1998.

38. Gorlick C, Brethour G: Welfare-To-work programs: A national inventory. Ottawa, Canada: Canadian Council on Social Development; 1998.

39. Shillington ER, Dennis D, Drummond A, Krahn H: Social assistance and paid employment in Alberta, 1993-1996. Edmonton, Alta: University of Alberta, Population Research Laboratory; 1998

40. Vosko L: Workfare temporaries: workfare and the rise of the temporary employment relationship in ontari. In Citizens or consumers?: social policy in a market society. Edited by Antony WA, Broad D. Halifax, NS: Fernwood; 1999:184-204.

41. Morris P, Michalopoulos C: Findings from the self-sufficiency project: effects on children and adolescents of a program that increased employment and income. J App/ Dev Psychol 2003, 24(2):201-239.

42. Ford R, Gyarmati D, Foley K, Tattrie D, Jimenez L: Can work incentives Pay for themselves? final report on the self-sufficiency project for welfare applicants. Ottawa: Social REsearch Demonstration Corportation; 2003.

43. Bloom D, Michalopoulos C: Manpower demonstration RC: How welfare and work policies affect employment and income: A synthesis of research. New York, NY: Manpower Demonstration Research Corporation; 2001.

44. Michalopoulos C, Social Research and DC: Making work Pay: final report on the self-sufficiency project for long-term welfare recipients. Ottawa, Canada: Social Research and Demonstration Corporation; 2002.

45. Gennetian LA, Miller C: Children and welfare reform: a view from an experimental welfare program in Minnesota. Child Dev 2002, 73(2):601-620.

46. Brooten D, Youngblut JM, Brown L, Finkler SA, Neff DF, Madigan E: A randomized trial of nurse specialist home care for women with high-risk pregnancies: outcomes and costs. Am J Manag Care 2001, 7(8):793-803.

47. Chase-Lansdale PL, Moffitt RA, Lohman BJ, Cherlin AJ, Coley RL, Pittman LD, Roff J, Votruba-Drzal E: Mothers' transitions from welfare to work and the wellbeing of preschoolers and adolescents. Science 2003, 299(5612):1548-1552.

48. Gibson M, Thomson H, Banas K, Bambra C, Fenton C, Bond L: Welfare to work interventions and their effects on health and well-being of lone parents and their children. Cochrane Database of Syst Rev 2012(5): CD009820. doi:10.1002/14651858.CD009820.

49. Wright S: Welfare-to-work, agency and personal responsibility. J Soc Policy 2012, 41(2):309-328.

50. Gazso A: Moral codes of mothering and the introduction of welfare-towork in Ontario. Can Rev Sociol 2012, 49(1):26-49.

51. Fothergill S: Welfare-to-work isn't working. People, Place Policy 2013, 7 (2):61-65.

52. Breitkreuz RS, Williamson DL, Raine KD: Dis-integrated policy: welfare-to-work participants' experiences of integrating paid work and unpaid family work. Community, Work \& Fam 2010, 13(1):43-69.

53. Cook K: Neoliberalism, welfare policy and health: a qualitative meta-synthesis of single parents' experience of the transition from welfare to work. Health (LOND) 2012, 16(5):507-530.

54. Vickery DM, Kalmer H, Lowry D, Constantine M, Wright E, Loren W: Effect of a self-care education program on medical visits. JAMA 1983, 250(21):2952-2956.

55. Browne G, Scarpa J, Ewart B, Schuster M, Edwardh J, Boily L: Investments in comprehensive programming: services for children and single parent mothers on welfare Pay for themselves within One year. In Our children's future: child care policy in Canada. Edited by Cleveland G, Krashinsky M. Toronto: University of Toronto Press, c2001; 2000:334-346.

56. Lorig K, Kraines RG, Brown BW Jr, Richardson N: A workplace health education program that reduces outpatient visits. Med Care 1985 23(9):1044-1054

57. Golaszewski T, Snow D, Lynch W, Yen L, Solomita D: A benefit-to-cost analysis of a work-site health promotion program. J Occup Med 1992, 34(12):1164-1172.

58. Lorig KR, Mazonson PD, Holman HR: Evidence suggesting that health education for self-management in patients with chronic arthritis has sustained health benefits while reducing health care costs. Arthritis Rheum 1993, 36(4):439-446.

59. Bischoff $R$, Sprenkle D: Dropping out of marriage and family therapy: a critical review of research. Fam Process 1993, 32(3):353-375.

60. Britton JA, Gammon MD, Kelsey JL, Brogan DJ, Coates RJ, Schoenberg JB, Potischman N, Swanson CA, Stanford JL, Brinton LA: Characteristics associated with recent recreational exercise among women 20 to 44 years of age. Women Health 2000, 31(2-3):81-96. 
61. Steele L, Dewa C, Lee K: Socioeconomic status and self-reported barriers to mental health service Use. Can J Psychiatr 2007, 52(3):201-206.

62. Janicke DM, Finney JW, Riley AW: Children's health care use: a prospective investigation of factors related to care-seeking. Med Care 2001, 39(9):990-1001.

63. Offord DR, Boyle MH, Szatmari P, Rae-Grant NI, Links PS, Cadman DT, Byles JA, Crawford JW, Blum HM, Byrne C: Ontario child health study. II. Six-month prevalence of disorder and rates of service utilization. Arch Gen Psychiatry 1987, 44(9):832-836.

64. Kessler RC, McGonagle KA, Zhao S, Nelson CB, Hughes M, Eshleman S, Wittchen HU, Kendler KS: Lifetime and 12-month prevalence of DSM-III-R psychiatric disorders in the united states. Results from the national comorbidity survey. Arch Gen Psychiatry 1994, 51(1):8-19.

65. Olds D, Kitzman H, Cole R, Robinson J: Theoretical foundations of a program of home visitation for pregnant women and parents of young children. J Community Psychol 1997, 25(1):9-25.

66. Osborn RN, Hagedoorn J: The institutionalization and evolutionary dynamics of interorganizational alliances and networks. Acad Manage J 1997, 40(2, Special Research Forum on Alliances and Networks):261-278.

67. Oliver AL, Ebers M: Networking network studies: an analysis of conceptual configurations in the study of inter-organizational relationships. Organ Stud 1998, 19(4):549-583.

68. Browne G, Roberts J, Byrne C, Gafni A, Weir R, Majumdar B: The costs and effects of addressing the needs of vulnerable populations: results of 10 years of research. Can J Nurs Res 2001, 33(1):65-76.

69. Browne G, Roberts J, Gafni A, Haldane S, Thomas I, Schuster M, Underwood J, Watt S, Rennick K, Ewart B: Benefiting all beneficiaries of social assistance: the 2-year effects and expense of subsidized versus nonsubsidized quality child care and recreation. Natl Acad Pract Forum 1999, 1(2):131-142.

70. Organization for Economic Cooperation and Development (OECD): Strategic governance and policy-making: Building policy coherence. Paris, France: Organization for Economic Cooperation and Development; 2000.

71. World Health Organization: The world health report: health in the 21st century: A vision for All. Geneva: World Health Organization; 1998.

72. World Health Organization: Primany HealthCare: report of the international conference on primary health care. Alam-Alta: World Health Organization; 1978.

73. Olds DL, Henderson CR Jr, Tatelbaum R, Chamberlin R: Improving the life-course development of socially disadvantaged mothers: a randomized trial of nurse home visitation. Am J Public Health 1988, 78(11):1436-1445.

74. Silver EJ, Ireys HT, Bauman LJ, Stein REK: Psychological outcomes of a support intervention in mothers of children with ongoing health conditions: the parent-to-parent network. J Community Psychol 1997, 25(3):249-264.

75. Witt PA, Crompton JL: Recreation programs that work for at risk youth: The challenge of shaping the future. State College, Pa: Venture Publishing, Incorporated; 1996.

76. Blair C, Ramey CT, Hardin JM: Early intervention for low birthweight, premature infants: participation and intellectual development. Am J Ment Retard 1995, 99(5):542-554

77. Olds D, Henderson CR Jr, Cole R, Eckenrode J, Kitzman H, Luckey D, Pettitt L, Sidora K, Morris P, Powers J: Long-term effects of nurse home visitation on children's criminal and antisocial behavior: 15-year follow-up of a randomized controlled trial. JAMA 1998, 280(14):1238-1244.

78. Pless IB, Satterwhite B: Chronic illness in childhood: selection, activities and evaluation of Non-professional family counselors. Clin Pediatr (Phila) 1972, 11(7):403-410.

79. Dunst CJ, Trivette CM, Deal AG: Supporting \& strengthening families: methods, strategies and practices. Northampton, MA : Brookline Books; 1994

80. Drummond J, Kysela GM, McDonald L, Alexander J, Fleming D: Risk and resiliency in two samples of Canadian families. Health Can Soc 1996, 4(1):117-151.

81. Comer JP: School power: implications of an intervention project. New York: Free Press; 1995

82. Marx E, Wooley S, Northrop D: Health Is academic: A guide to coordinated school health programs. Columbia University: Teachers College Press, Teachers College; 1998

83. Reynolds AJ, Mavrogenes NA, Bezruczko N, Hagemann M: Cognitive and family-support mediators of preschool effectiveness: a confirmatory analysis. Child Dev 1996, 67(3):1119-1140.

84. Offord D, Jones M: Skill development: a community intervention program for the prevention of anti-social behavior. In Childhood psychopathology and developmen. Edited by Earls F, Guze SB, Barrett JE. New York, NY: Raven; 1983:165-188.

85. McKay SL, Reid IS, Tremblay MS, Pelletier R: The impact of recreation on youth in transition to adulthood: a focus on youth at risk. In Youth in transition: perspectives on research and policy. Edited by Galaway B, Hudson J. Toronto, Canada: Thompson Educational Publishing; 1996:234-292.

86. Martinek TJ, Hellison DR: Fostering resiliency in underserved youth through physical activity. Quest 1997, 49(1):34-49.

87. Offord D, Hanna E, Hoult L: Recreation and the development of children and youth: a discussion paper. Paper [http://lin.ca/sites/default/files/ attachments/child.htm]

88. Timmons BW, LeBlanc AG, Carson V, Connor Gorber S, Dillman C, Janssen I, Kho ME, Spence JC, Stearns JA, Tremblay MS: Systematic review of physical activity and health in the early years (aged 0-4 years). Appl Physiol, Nutr Metab 2012, 37(4):773-792.

89. Howie LD, Lukacs SL, Pastor PN, Reuben CA, Mendola P: Participation in activities outside of school hours in relation to problem behavior and social skills in middle childhood. J Sch Health 2010, 80(3):119-125.

90. Vogler S, Davidson A, Crane L, Steiner J, Brown JM: Can paraprofessional home visitation enhance early intervention service delivery? J Dev Behav Pediatr 2002, 23:208-216.

91. Ginsburg KR: The importance of play in promoting healthy child development and maintaining strong parent-child bonds. Pediatrics 2007, 119(1):182.

92. Brown SJ: Nursing intervention studies: a descriptive analysis of issues important to clinicians. Res Nurs Health 2002, 25(4):317-327.

93. Browne G, Byrne C, Roberts J, Gafni A, Majumdar B, Kertyzia J: Convergence Why Ontario should develop community-based models of integrated service for school-aged children. A discussion paper. Hamilton, Ont: he System-Linked Research Unit on Health and Social Service Utilization, McMaster University; 2001.

94. Kazdin AE, Kraemer HC, Kessler RC, Kupfer DJ, Offord DR: Contributions of risk-factor research to developmental psychopathology. Clin Psychol Rev 1997, 17(4):375-406.

95. Kazdin AE: Bridging the enormous gaps of theory with therapy research and practice. J Clin Child Psychol 2001, 30(1):59-66.

96. Ciliska D, Hayward S, Thomas H, Mitchell A, Dobbins M, Underwood J, Rafael A, Martin E: A systematic overview of the effectiveness of home visiting as a delivery strategy for public health nursing interventions. Can J Public Health 1996, 87(3):193-198.

97. Families First Edmonton: Families first Edmonton service delivery toolkit. Edmonton: Families First Edmonton; 2010.

98. Canadian Agency for Drugs and Technologies in Health: Guidelines for the economic evaluation of health technologies. 3rd edition. Ottawa: Canadian Agency for Drugs and Technologies in Health; 2006.

99. Muthén BO, Curran PJ: General longitudinal modeling of individual differences in experimental designs: a latent variable framework for analysis and power estimation. Psychol Methods 1997, 2(4):371-402

doi:10.1186/1472-6963-14-223

Cite this article as: Drummond et al:: The protocol for the Families First Edmonton trial (FFE): a randomized community-based trial to compare four service integration approaches for families with low-income. BMC Health Services Research 2014 14:223.

\section{Submit your next manuscript to BioMed Central and take full advantage of:}

- Convenient online submission

- Thorough peer review

- No space constraints or color figure charges

- Immediate publication on acceptance

- Inclusion in PubMed, CAS, Scopus and Google Scholar

- Research which is freely available for redistribution 